\title{
Arkansas: A Leading Laboratory for Health Care Payment and Delivery System Reform
}

The mission of The Commonwealth Fund is to promote a high performance health care system. The Fund carries out this mandate by supporting independent research on health care issues and making grants to improve health care practice and policy. Support for this research was provided by The Commonwealth Fund. The views presented here are those of the authors and not necessarily those of The Commonwealth Fund or its directors, officers, or staff.

For more information about this brief, please contact:

Deborah Bachrach, J.D.

Partner

Manatt, Phelps \& Phillips, LLP

dbachrachamanatt.com
To learn more about new publications when they become available, visit the Fund's website and register to receive email alerts.

Commonwealth Fund pub. 1766 Vol. 20

\author{
Deborah Bachrach, Lammot du Pont, and Mindy Lipson \\ Manatt, Phelps \& Phillips, LLP
}

\begin{abstract}
As states' Medicaid programs continue to evolve from traditional fee-for-service to value-based health care delivery, there is growing recognition that systemwide multipayer approaches provide the market power needed to address the triple aim of improved patient care, improved health of populations, and reduced costs. Federal initiatives, such as the State Innovation Model grant program, make significant funds available for states seeking to transform their health care systems. In crafting their reform strategies, states can learn from early innovators. This issue brief focuses on one such state: Arkansas. Insights and lessons from the Arkansas Health Care Payment Improvement Initiative (AHCPII) suggest that progress is best gained through an inclusive, deliberative process facilitated by committed leadership, a shared agreement on root problems and opportunities for improvement, and a strategy grounded in the state's particular health care landscape.
\end{abstract}

\section{OVERVIEW}

Increasingly, states are moving beyond their traditional Medicaid programs to embrace new roles as leaders of statewide payment and delivery system transformation. The search for statewide solutions is fueled by cost pressures, health system inefficiencies, and poor outcomes, and enabled by expansions in coverage and the availability of substantial federal funding. ${ }^{1}$ In this issue brief, we examine the Arkansas Health Care Payment Improvement Initiative (AHCPII), which, while predating coverage expansion, both supported and was strengthened by the state's decision to expand Medicaid coverage through qualified health plans (QHPs). As such, AHCPII offers important lessons for policymakers.

In 2011, Arkansas began a process to address the challenges and opportunities presented by the state's existing health care delivery and payment environment. What emerged was a statewide payment reform initiative that spanned outpatient and inpatient care. ${ }^{2}$ AHCPII consists of three components: 1) patient-centered medical homes (PCMHs), 2) Health Homes for chronically ill and other individuals with complex health care needs, and 3) payment and delivery models based on episodes of care. While these programmatic elements were developed in response to Arkansas's health 
care landscape in particular, the process by which they were developed, funded, and implemented, as well as their most critical attributes, is probative beyond the state's borders.

This issue brief addresses AHCPII's origin, key components, evolution, and replication potential. It focuses on payment and delivery reform as well as the interrelationship between AHCPII and health insurance expansion. The brief is informed by published research, state documents, and interviews with the leadership and key stakeholders in Arkansas.

\section{AHCPII Reforms Seek to Address Fiscal, Population, and Provider Challenges}

In 2010, Arkansas officials faced a triple threat: a confluence of fiscal, population, and provider system challenges. A potential Medicaid Trust Fund shortfall loomed as enhanced federal matching dollars (FMAP) were coming to an end, with deficits projected as high as $\$ 400$ million. Arkansas's population suffered from pervasive chronic disease: more than 50 percent of Arkansas's adults had at least one chronic disease. ${ }^{3}$ In addition, Arkansas's provider community was fragmented, with 60 percent of physicians in practices of five or fewer physicians dispersed among a largely rural population with few formal structural connections between physicians and hospitals, other providers, or one another. An uninsured rate that exceeded the national average ${ }^{4}$ and a Medicaid program with the lowest eligibility levels in the nation added to Arkansas's challenges.

While faced with fiscal and structural challenges, Arkansas benefited from government leaders who understood the Arkansas health care market, had the experience and expertise to diagnose the drivers of the existing challenges, and proved adept at designing a program that was responsive to stakeholders. ${ }^{5}$

In 2011, Arkansas Medicaid was almost entirely a fee-for-service system with low payment rates and substantial reliance on provider taxes and supplemental payments. The architects of Arkansas's statewide health system transformation determined that the traditional options for averting a Medicaid shortfall (e.g., rate cuts, reductions of benefits, introduction of Medicaid managed care) were unpalatable and that an alternative path was needed. In crafting a solution that could extend throughout the state and entire health system, the state benefited from a high degree of market concentration in two local payers-Arkansas Blue Cross Blue Shield (the largest in the state) and QualChoice-representing 80 percent of the commercial market. ${ }^{6}$ With comparatively fewer payers, Arkansas could more easily achieve commonality across insurers' initiatives and more effectively influence delivery reform. Moreover, because the dominant plans were local, they had greater latitude to respond to state-specific payment models.

The state convened stakeholders to develop a common vision and framework for health system transformation. At the outset, providers and payers agreed on three foundational propositions:

1. the trajectory of health care costs was unsustainable;

2. there were inefficiencies in the system that, once corrected, could result in shared savings; and

3. the traditional fee-for-service model perpetuated misaligned incentives and had to be replaced with a value-based system.

Medicaid's fiscal crisis and similar pressures in the private sector presented an opportunity to integrate individual payer efforts into a collective framework for reform. 
An especially important feature of the state's approach was its full commitment to a systemic, statewide transformation. In his February 11, 2011, letter to HHS Secretary Sebelius, Governor Beebe framed the proposed systemwide change as follows:

Arkansas would like to try a different approach—a partnership between Medicaid, Medicare, and private insurers that would fundamentally transform the fee-for-service system. The plan is bold. It is not based on small-scale pilot projects, because such projects cannot yield broad-based cost and quality improvements in the near future. ${ }^{7}$

Emerging from the deliberative process was the Arkansas Health Care Payment Improvement Initiative, which placed providers at the helm of reform. ${ }^{8}$ Rather than introducing additional layers of oversight and regulation, AHCPII incentivizes providers through greater accountability for costs and quality and concomitant opportunities to participate in generated savings that align interests across health care providers, purchasers, and payers.

With the stated goal of moving most public and private health care expenditures to a value-based system in four years, the state set an incremental course for implementing AHCPII. It first addressed pressing priorities in primary and acute care, leaving for a later phase long-term care and the integration of public health into its delivery and payment reforms. In a pragmatic approach to attaining what was feasible in the shorter term, the state postponed tackling Medicaid's antiquated per diem payment methodology and hospital supplemental payments. ${ }^{9}$

The state has worked to expand payer involvement to include self-insured plans. The self-insured Arkansas State Public Employee and Public School Health Insurance Plan “Arkansas Blue Cross Blue Shield developed a medical home pilot program in 2010 with five practices. While initial results were promising, we needed involvement of other payers to fully support the practices. The Comprehensive Primary Care initiative and the state $\mathrm{PCMH}$ program offered solutions to get to scale more broadly and at a quicker pace."

Alicia Berkemeyer, Director of Enterprise Networks Special Projects, Arkansas Blue Cross Blue Shield now requires participation of its third party administrators, and Arkansas Blue Cross Blue Shield extended episodic payments to its self-insured accounts. In addition, the largest private sector employer in the state, Walmart, has committed to participate in AHCPII. ${ }^{10}$

AHCPII consists of three complementary components, which are summarized in Exhibit 1 and described in detail in Appendices B, C, and D. 


\section{Exhibit 1. Summary of Arkansas Health Care Payment Improvement Initiative Components}

\section{Patient-Centered Medical Home}

Health Homes

Episode-Based Payments

Overview

Patient-centered medical homes (PCMHs) are teams of providers who take responsibility for the overall health of assigned patients. A patient's team is led by a designated primary care doctor who communicates with other clinical and administrative professionals to better coordinate patients' care.
Health Homes extend the medical home care coordination approach to a subset of chronically ill patients who have the most complex or extensive needs. When implemented, Arkansas's Health Home program will serve patients with multiple chronic conditions, including those who need behavioral health care services or long-term services and support (LTSS).
The AHCPII outpatient payment component is a retrospective episodebased model that establishes a "principal accountable provider" (PAP) identified by the payer, who is responsible for the quality and costs of the health services to treat a particular diagnosis over a defined period of time.

\section{Key Features}

AHCPII includes two PCMH initiatives: 1) a federally funded Medicare Comprehensive Primary Care (CPC) 2012 initiative, which includes five payers (Medicare, Arkansas Medicaid, Arkansas Blue Cross and Blue Shield, Humana, and QualChoice of Arkansas) and 69 participating primary care practices; $^{12}$ and 2) a 2014 Medicaid-led $\mathrm{PCMH}$ initiative.

Practices participating in PCMH initiatives receive payments to support care coordination by two mechanisms: 1) per member per month (PMPM) payments to providers for care coordination and practice transformation, and 2) shared savings.
Health Home payments will include a risk-adjusted, PMPM fee to be assessed by the state every two years based on costs, savings, and outcomes. A portion of the PMPM fee will depend on acceptable performance on process and outcome metrics for care management and coordination. ${ }^{13}$
Treating providers submit claims and are reimbursed on a fee-for-service basis; gain-sharing or penalties are determined by comparing performance to a predetermined target fee for each episode.

The construction and implementation of episodes are largely the same across payers; slight variation occurs in the thresholds for shared savings and payment amounts. $^{14}$
Implementation Status

In October 2012, participating practices in the $\mathrm{CPC}$ initiative began receiving PMPM payments for care coordination. Voluntary enrollment of additional practices began in late 2013 and has continued through 2014. In January 2014, practices in the Medicaid initiative began receiving PMPM payments. In 2015, practices will begin receiving PMPM payments for Qualified Health Plan enrollees. CPC practices are also eligible for shared savings if they have a minimum of 5,000 patients enrolled in a PCMH. ${ }^{15}$
The Health Home rollout is expected to launch in 2014 and proceed in three waves through 2015. The first wave is for adults with developmental disabilities; the second covers individuals requiring LTSS; and the third covers individuals with serious mental illness. $^{16}$
Payment changes for designated episodes of care have been rolled out incrementally among three payers-Medicaid, Arkansas Blue Cross Blue Shield, and QualChoice. From 2012 to 2013, participating payers launched changes for eight episodes of care on a statewide basis. ${ }^{17}$

\begin{tabular}{lll}
\hline & \multicolumn{1}{c}{ Preliminary Results } & \\
\hline $\begin{array}{l}\text { As of December 2013, more than } 600 \\
\text { providers had signed up to participate in } \\
\text { the Medicaid-led PCMH initiative, providing }\end{array}$ & $\begin{array}{l}\text { The Health Home component is still in } \\
\text { development, and results are not available. }\end{array}$ & $\begin{array}{l}\text { Results from the first three episodes of } \\
\text { care to be paid under the new payment } \\
\text { method include increased adherence to } \\
\text { care to approximately } 250,000 \text { Medicaid }\end{array}$ \\
$\begin{array}{l}\text { members, or } 72 \text { percent of the Medicaid } \\
\text { population eligible to participate in the }\end{array}$ & $\begin{array}{l}\text { in unnecessary procedures, and reduction } \\
\text { program. In addition, the willingness of } \\
\text { smaller practices to partner with other }\end{array}$ \\
$\begin{array}{l}\text { providers in virtual pools for shared savings } \\
\text { eligibility has increased the ability of these } \\
\text { providers to improve care coordination. }\end{array}$ & \\
\end{tabular}




\section{AHCPII Moving Forward}

Within the next three years, Arkansas expects episode-based payments to account for 50 percent to 70 percent of the state's total health care spending for acute care and complex chronic conditions. ${ }^{20}$ By 2017, Arkansas expects PCMHs to serve the majority of Arkansans. ${ }^{21}$

AHCPII expansion also will be boosted significantly by Arkansas's decision to expand Medicaid through QHPs in the state's federally facilitated insurance marketplace. Under a federal waiver, Arkansas uses funds authorized under the Affordable Care Act to expand adult Medicaid coverage through QHPs, referred to as the Private Option. The

"AHCPII is appealing to employers because it introduces price signals into a market that typically does not have price signals."

Randy Zook, President and Chief Executive Officer, Arkansas State Chamber of Commerce

Arkansas Insurance Department requires QHP issuers to

participate in the Private Option and, beginning in 2015, in AHCPII's PCMH program. ${ }^{22}$

These requirements will vastly increase the reach of the PCMH program; as of July 2014, over 170,000 individuals enrolled in QHPs through the Private Option, ${ }^{23}$ and another 40,000 enrolled through the marketplace. ${ }^{24}$ As the number of patients enrolled in a PCMH grows, practices will be eligible for additional per member per month (PMPM) payments, providing additional resources for practice transformation. In addition, AHCPII's success in addressing the underlying problems of the state's Medicaid program generated support for the coverage expansion. At this point, "the Private Option and AHCPII are now symbiotic: one accelerates and leverages the other," noted former state Medicaid director Andy Allison. ${ }^{25}$

\section{AHCPII Has Lessons for Other States}

While Arkansas's success is grounded in reforms that address its particular health care landscape, there are insights that can inform other states' health system delivery and payment reforms. These include:

- Leadership. There is no substitute for high-level leadership from the state's governor and his/her key advisors who can command the respect and attention of key stakeholders. In Arkansas, the governor identified payment and delivery system reform as a top priority, and achieved progress through focused leadership and dedicated resources across multiple state offices, including Medicaid, human services, insurance, the surgeon general, and the independent Arkansas Center for Health Improvement.

- Inclusive and Ongoing Stakeholder Participation. Comprehensive transformation of a state's health care system requires that providers, payers, and other key stakeholders are meaningfully engaged from inception through implementation. Rather than attempt to exercise its authority unilaterally, Arkansas engendered trust by creating and maintaining a transparent, collaborative process involving the health care system's multiple stakeholders.

- Common Principles. Stakeholder consensus on key principles is critical, providing a common lens for assessing progress and resolving problems. Arkansas galvanized participation and maintains ongoing engagement through broadbased agreement on the root causes of the health care quality and cost challenges.

- Ambitious but Realistic Reforms. While important for health reform to be bold to garner and maintain attention, it must take into consideration the health care system's capabilities and be paced pragmatically. AHCPII was designed to move the state's delivery system in dramatic ways; it was not, however, predicated on uprooting the current delivery system. Reforms were phased in over time, with a process in place to identify workable solutions and respond to unanticipated events. 
- Use of State Levers to Drive Multipayer Involvement. To ensure the breadth and depth of payer and provider participation required for statewide health system reform, states must strategically deploy their purchasing and regulatory authorities across agencies (e.g., Medicaid, insurance, public health, and state employees), reinforced when needed by the state leadership's bully pulpit. Only a handful of states have a payer landscape like Arkansas's, dominated by relatively few local health plans; however, all states can draw upon Arkansas's use of state leadership to engage the commercial marketplace through large self-insured employers. And, through their certification requirements, state insurance agencies or state-based marketplaces can require QHPs to engage in value-based purchasing. Similarly, states using managed care in their Medicaid programs can accomplish reform through contractual requirements with their Medicaid managed care organizations, ${ }^{26}$ much the same way that Arkansas has done with QHPs.

- Payment Reform Coupled with Expanded Coverage. Meaningful system reform will be far more difficult, if not impossible, to achieve for states in which a significant number of residents remain uninsured. Arkansas initiated AHCPII prior to implementation of the Affordable Care Act. However, by expanding coverage through Medicaid premium assistance (the Private Option) and requiring QHP participation, the state dramatically changed its health care landscape: it extended access to affordable coverage to 250,000 adults, cut uncompensated care costs, expanded the pool of patients included under payment reform, and ultimately accelerated the state's reform efforts. ${ }^{27}$

- Funding. Funding generates interest in and enables reform. The AHCPII planning and implementation process benefited from substantial private and public funding. ${ }^{28}$ Going forward, other states can fund payment and delivery system reforms as a result of the availability of $\$ 730$ million for the next round of State Innovation Model grants and Delivery System Reform Improvement Payment Program waivers, with the technical support of the Medicaid Innovation Accelerator Program (IAP). ${ }^{29}$

\section{CONCLUSION}

Whether driven by the triple aim of improved patient care, improved health of populations, and reduced costs; budget pressures; Medicaid expansion; or a combination of all three, states are advancing their health systems' evolution toward value-based care. Although their health care landscapes, reform starting points, and pace vary, states can draw valuable lessons from the AHCPII experience. Among the seven lessons learned, state leadership and funding are central. With fully committed and experienced state leaders and the increased availability of federal funding for multistakeholder strategies, states can work out the details of reform though a process of engaged, collaborative planning and implementation. 


\section{APPENDIX A. LIST OF INTERVIEWEES}

Mike Beebe, Governor of Arkansas

Andy Allison, Ph.D., former Director, Arkansas Division of Medical Services (Arkansas Medicaid)

Alicia Berkemeyer, Director of Enterprise Networks Special Projects, Arkansas Blue Cross Blue Shield

William Golden, M.D., Medical Director, Arkansas Division of Medical Services (Arkansas Medicaid)

Michael Motley, Prevention Specialist, Health Care Finance, Arkansas Center for Health Improvement

Lonnie Robinson, M.D., Arkansas Academy of Family Physicians Board of Directors

Bo Ryall, President and CEO, Arkansas Hospital Association, and Paul Cunningham, Executive Vice President, Arkansas Hospital Association

Stephen Sorsby, M.D., Medical Director, QualChoice, and Mark Johnson, Vice President of Network Services, QualChoice

Joseph Thompson, M.D., Arkansas Surgeon General and Director, Arkansas Center for Health Improvement

Craig Wilson, Director of Access to Quality Care, Arkansas Center for Health Improvement

David Wroten, Executive Vice President, Arkansas Medical Society

Randy Zook, President and Chief Executive Officer, Arkansas State Chamber of Commerce 


\section{ApPENDIX B. AHCPII PATIENT-CENTERED MEDICAL HOMES}

Patient-centered medical homes (PCMHs) are teams of providers who take responsibility for the overall health of assigned patients. A patient's team is led by a designated primary care physician (PCP) who communicates with other clinical and administrative professionals to better coordinate patients' care. Through improved care coordination and communication, PCMHs are intended to help patients stay healthy, improve the quality of care they receive, and reduce costs. AHCPII consists of two PCMH initiatives:

1. Medicare's Comprehensive Primary Care (CPC) initiative, which was launched in October 2012 and includes five payers (Medicare, Arkansas Medicaid, Arkansas Blue Cross Blue Shield, Humana, and QualChoice of Arkansas) and 69 participating primary care practices with 275 providers across the state. ${ }^{30}$

2. A Medicaid-led PCMH initiative which began its first performance period in January 2014. To participate in the PCMH program in 2014, a practice must serve at least 300 Medicaid patients. By 2015, all qualified health plan (QHP) issuers will be required to participate in the AHCPII, which includes "provid[ing] support for patient-centered medical home[s]." 31

Though the CPC and Medicaid PCMH initiatives have different requirements, the overall objectives are consistent:

- include most of a provider's patient panel (e.g., 80 percent) in the medical home to ensure that the provider is well invested in PCMH principles;

- ensure that primary care providers have a deep understanding of current performance and drivers of value across their patient panel;

- create opportunities for a broad spectrum of PCMHs, with different starting points, to share in meaningful rewards; and

- provide guidance on practice transformation and care coordination without being overly prescriptive, allowing practices to focus on cost and quality of care. ${ }^{32}$

AHCPII is implementing PCMHs in three successive waves between 2012 and 2015, consistent with AHCPII's phased enrollment of physician practices. Once enrolled in AHCPII, participating practices begin receiving payments under the per member per month (PMPM) payment model. ${ }^{33}$

\section{Reimbursement Under the PCMH Model}

Practices participating in the PCMH program receive payments to support care coordination through two mechanisms: PMPM payments and shared savings. The payment amount per member varies by the type of PCMH initiative.

Under the CPC initiative, payers provide a PMPM payment to underwrite the costs of practice transformation and incentivize providers to practice effective population health management. Under the Medicaid initiative, the state pays a small portion of the total PMPM amount to a technical support vendor to promote practice transformation. ${ }^{34}$

As part of the AHCPII, all PCMH practices in either the Medicare or Medicaid initiative also can receive payments based on cost savings. AHCPII's shared savings model includes "upside payments" (i.e., providers share in expected savings, but are not penalized if payments exceed risk-adjusted baseline costs). To qualify for shared savings, practices must have at least 5,000 patients, either independently or by entering virtual risk pools with other practices, ${ }^{35}$ and must meet the state's quality metrics. ${ }^{36}$ 


\section{PCMH Results}

As of December 2013, the Medicaid-led PCMH program included over 600 primary care physicians covering more than 250,000 Medicaid members (72 percent of all members eligible for a PCMH). ${ }^{37}$ In February 2014, practices in the Medicaid initiative received their first quarterly PCMH reports showing quality and cost data. ${ }^{38}$

In addition to the brisk pace of enrollment, the public and private payers have been surprised and encouraged by providers' willingness to enter into virtual risk pools for shared savings. Not only do the risk pools generate revenue for providers, the virtual arrangements create partnerships that serve as a valuable foundation for care coordination in a market with a significant percentage of small, independent practices. ${ }^{39}$ 


\section{APPENDIX C. AHCPII HEALTH HOMES}

Authorized under Section 2703 of the Affordable Care Act, Health Homes extend the PCMH care coordination approach to a subset of chronically ill patients who have the most complex or extensive needs.

As a component of the Arkansas Health Care Payment Improvement Initiative (AHCPII), the Health Home program will serve patients with multiple chronic conditions, including those who may need behavioral health care services or long-term services and support (LTSS). Health Homes will be accountable for the range of services required by individuals with special needs - the frail elderly, those with developmental disabilities, those with severe and persistent mental illness, and other high-need behavioral health patients. ${ }^{40}$

For patients who have developmental disabilities (DD) or behavioral health (BH) needs or who require LTSS, the patient's primary provider of services over time, i.e., the "lead provider" will manage the Health Home. ${ }^{41}$ The lead provider will be accountable for improving health outcomes, streamlining the care planning process, and developing and executing an integrated plan spanning medical care and DD, LTSS, or BH services.

AHCPII's Health Home rollout is expected to occur in three waves between 2014 and 2015.42

\section{Health Home Reimbursement}

Health Home payments will include a risk-adjusted, PMPM fee to be assessed by the state every two years based on costs, savings, and outcomes. A portion of the fee will depend upon on acceptable performance on process and outcome metrics for care management and coordination. ${ }^{43}$

Quality assurance for Health Homes will be achieved through multiple measures ranging from patient experience, care coordination, and preventive health for at-risk populations. Aggregate performance measures will be reported to providers and used to determine provider eligibility for incentive payments (shared savings, per member per month care coordination fees, or both). While DD, BH, and LTSS Health Homes will provide similar health home functions and activities, provider requirements, quality measures, and outcomes will reflect the unique needs of each population. ${ }^{44}$ 


\section{APPENDIX D: AHCPII'S EPISODE-BASED PAYMENTS}

Arkansas's payment strategy for acute care delivery is built on the episode-based payment, under which a single fee is paid for all the services a patient needs during an episode of care. Episodes - their duration and range of services included-are defined through an extensive stakeholder engagement process, a review of evidence-based guidelines, and an examination of claims data in consultation with both state staff and national experts. A provider most responsible for the quality and cost of care provided to a patient for a particular episode of care is designated as the "principal accountable provider," or PAP, and shares in an episode's savings or excess costs.

Arkansas designed its episodic payment system to target care conditions that exhibited clinical practice variation or treatment inefficiencies. For each episode, work groups analyzed Arkansas-specific data, created quality metrics and diagnosis exclusion criteria, determined risk adjustment, defined outliers, and identified potential adjustments based on severity, transfer cases, clinical factors, and facility per diem normalization. ${ }^{45}$

Currently, three payers-Medicaid, Arkansas Blue Cross Blue Shield, and QualChoice—are making episodebased payments for more than a dozen episodes of care the state designated for payment reform. ${ }^{46}$

The construction and implementation of episodes are largely the same across payers; slight variation occurs in the thresholds for shared savings and payment amounts. ${ }^{47}$

\section{Reimbursement Under the Episode-Based Payment Model}

To reward coordinated, team-based, high-quality care for all services related to an episode, payers identify a PAP, who is accountable for all prespecified services across the episode's duration. Physicians designated as PAPs vary depending on the episode and its treatment. For example, PAPs for hip and knee replacements are orthopedic surgeons; ${ }^{48}$ PAPs for an ADHD episode can be a primary care physician, mental health professional, or an agency like the Rehabilitative Services for Persons with Mental Illness provider organization, depending on the treatment. ${ }^{49}$

The new payment model works under the existing fee-for-service system. For each episode, all treating providers continue to file claims and are reimbursed according to each payer's established fee schedule. ${ }^{50}$ Gain-sharing or penalties are determined by comparing the PAP's performance to a predetermined target fee for each episode. For each episode, the payer determines "commendable" and "acceptable" cost thresholds. PAPs with average costs below the commendable threshold are eligible for gain-sharing only if they perform well enough on quality measures; alternatively, PAPs with average costs above the acceptable threshold are assessed penalties. PAPs with average costs between acceptable and commendable do not receive gain-sharing or penalties. ${ }^{51}$

Physician participation in episode-based payment implementation is not voluntary; a provider that bills for a triggering service - that is, a service specified in a given episode's definition-is included in the episode profiling process. Each PAP must meet a minimum caseload per episode (which varies by episode) to qualify for the opportunity to receive gain- or risk-sharing. ${ }^{52}$ To aid in implementation, PAPs receive a baseline report showing how their quality and cost metrics compare with those of other providers in the state and with the gain-sharing thresholds established by each payer. PAPs also receive quarterly reports for each episode that show comparative performance for costs and quality.

\section{Episode-Based Payment Model Results}

Stakeholder feedback suggests that the episode-based payment component has introduced price signals — that is, sensitivity to cost-into the health system. Although Medicaid pays a fixed rate for services within an episode, commercial plans negotiate payment rates with providers; this creates cost variability and incentivizes PAPs to refer patients to facilities that have lower contracted rates.

From 2012 to 2013, participating payers launched eight episodes of care on a statewide basis. A review of Medicaid claims data and quality metrics showed the following results: 
- Increased screening for diabetes, HIV, Hepatitis B, and other conditions in pregnant women.

- From October 2012 through December 2012, a 29 percent drop in ADHD episode costs.

- Improved coding and oversight of stimulant medication to ensure prescriptions match diagnoses.

- Stabilized costs for congestive heart failure and total joint replacements.

- From October 2012 through September 2013, a 19 percent decrease in unnecessary antibiotic prescriptions for unspecified upper respiratory infections.

- An 18 percent reduction in multiple courses of antibiotics prescribed for sinusitis and other upper respiratory infections. ${ }^{53}$

As of June 2014, Arkansas's Department of Human Services reported almost $\$ 400,000$ in financial incentive payments to providers for meeting quality and efficiency goals and almost $\$ 600,000$ that providers are required to reimburse Arkansas Medicaid because their costs were not comparable to their peers' ${ }^{54}$ 


\section{NOTES}

1 Centers for Medicare and Medicaid Services, State Innovation Models Initiative: General Information, http://innovation.cms.gov/initiatives/state-innovations/; Centers for Medicare and Medicaid Services, Comprehensive Primary Care Initiative, http://innovation.cms.gov/initiatives/Comprehensive-Primary-Care-Initiative/; Centers for Medicare and Medicaid Services, Health Homes, http://www.medicaid.gov/Medicaid-CHIP-Program-Information/By-Topics/LongTerm-Services-and-Supports/Integrating-Care/Health-Homes/Health-Homes.html.

2 While a number of states have developed or deployed various statewide either outpatient or inpatient payment reform efforts, only Arkansas has deployed both. Four other states (Colorado, Maryland, New Jersey, and Oregon) have launched statewide, multipayer PCMH initiatives, and 15 states (Alabama, Idaho, Iowa, Maine, Maryland, Missouri, New York, North Carolina, Ohio, Oregon, Rhode Island, South Dakota, Vermont, Washington, and Wisconsin) have CMS-approved Health Home State Plan Amendments. Two states (Ohio and Tennessee) are developing plans to create a statewide, multipayer episode-based payment approach similar to that in Arkansas. Manatt Health Solutions analysis of Patient-Centered Primary Care Collaborative, "Primary Care Innovations and PCMH Map by State," http://www. pcpcc.org/initiatives/state, accessed July 8, 2014; Manatt Health Solutions analysis of Manatt Health Solutions analysis of Centers for Medicare and Medicaid Services, State Health Home CMS Proposal Status (effective June 2014), http:// www.medicaid.gov/State-Resource-Center/Medicaid-State-Technical-Assistance/Health-Homes-Technical-Assistance/ Downloads/HH-MAP_v34.pdf, accessed July 8, 2014; Manatt Health Solutions analysis of publicly available CMMI State Innovation Model plans, http://innovation.cms.gov/initiatives/state-innovations/, accessed July 8, 2014.

3 J. Thompson, "Building a Healthier Future for All Arkansans," Presentation at NASHP 25th Annual State Health Policy Conference, Oct. 16, 2012, http://www.nashpconference.org/wp-content/uploads/2012/presentations/ Thompson.20.Builing.Healthier.Arkansas.pdf, accessed June 27, 2014.

4 Henry J. Kaiser Family Foundation, Health Insurance Coverage of the Total Population, http://kff.org/other/Stateindicator/total-population/, accessed June 27, 2014.

5 Prior to his election in 2006, Governor Mike Beebe served on the board of a local hospital and was familiar with many of the challenges of health care delivery in the state. Arkansas also benefited from the legislatively created position of state surgeon general, an independent, cabinet-level advisor charged with identifying strategies and shaping policies to improve health in Arkansans. They were joined by experienced leadership at the Department of Human Services and its Medicaid agency (including two successive directors and the medical director), the Insurance Department, and the Arkansas Center for Health Improvement.

6 J. Thompson, interview with Manatt, June 2014; W. Golden, interview with Manatt, June 2014.

7 M. Beebe, Letter to Secretary Sebelius, Feb. 2011, http://www.paymentinitiative.org/referenceMaterials/Documents/ Governor\%20Mike\%20Beebe\%20AR\%20Medicaid\%20Transformation\%20Proposal.pdf, accessed June 27, 2014.

8 J. Thompson, interview with Manatt, June 2014.

9 Supplemental payments serve as a critical source of revenue to hospitals, especially safety-net hospitals, but are disconnected from the specific services provided to patients and delinked from the efficiency or quality of the care provided. Because of this disconnect, supplemental payments potentially dilute the incentives built into AHCPII's market-based reforms.

10 On January 10, 2013, Walmart agreed to serve on the AHCPII Employer Advisory Council and committed \$670,000 to fund the development and distribution of information to the public and underwrite an annual statewide tracking report that evaluates the project; Walmart, "Walmart Joins Arkansas Health Care Payment Improvement Initiative," Jan. 2013, http://news.walmart.com/news-archive/2013/01/10/walmart-joins-arkansas-health-care-payment-improvement-initiative, accessed July 8, 2014.

11 J. Thompson, W. Golden, R. Hill et al., “The Arkansas Payment Reform Laboratory," Health Affairs Blog, March 2014, http://healthaffairs.org/blog/2014/03/18/the-arkansas-payment-reform-laboratory/, accessed June 27, 2014. 
12 Centers for Medicare and Medicaid Services, Comprehensive Primary Care Initiative: Arkansas: Statewide, http://innovation.cms.gov/initiatives/Comprehensive-Primary-Care-Initiative/Arkansas.html, accessed June 27, 2014.

13 Arkansas Division of Medical Services, Arkansas Behavioral Health Home State Plan Amendment; Preliminary Working Draft, March 2014, http:/www.paymentinitiative.org/referenceMaterials/Documents/DRAFT\%20-\%20AR\%20 Behavioral\%20Health\%20Home\%20State\%20Plan\%20Amendment\%20-\%2003-11-14.pdf, accessed Aug. 11, 2014; Arkansas Department of Human Services, Arkansas Health System Transformation State Innovation Plan (Little Rock, Ark.: Arkansas DHS, Sept. 2012), http://www.paymentinitiative.org/referenceMaterials/Documents/SIM\%20III.\%20 \%20State\%20Innovation\%20Plan\%202012\%2009\%2021\%20\%20FINAL\%20-\%20TO\%20SUBMIT.pdf, accessed Aug. 11, 2014.

14 Thompson, Golden, Hill et al., “The Arkansas Payment Reform Laboratory,” 2014.

15 W. Golden, J. Thompson, S. Olson et al., "Patient-Centered Medical Homes in Arkansas," Health Affairs Blog, May 2014, http://healthaffairs.org/blog/2014/05/20/patient-centered-medical-homes-in-arkansas/, accessed June 27, 2014.

16 C. Wilson and M. Motley, interview with Manatt, July 2014.

17 State of Arkansas, Episode Spreadsheet with Notes: For Medicaid, Work Has Occurred on 24 Episodes, with 13 Having Gone Live, http://www.paymentinitiative.org/referenceMaterials/Documents/Episode\%20Spreadsheet\%20-\%20 24\%20with\%20notes.pdf, accessed July 8, 2014.

18 Golden, Thompson, Olson et al., "Patient-Centered Medical Homes in Arkansas," 2014; and Arkansas Hospital Association Medicaid Subcommittee Meeting, June 5, 2014.

19 Arkansas Department of Human Services, Review Shows Payment Improvement Initiative Advancing Patient Care, Decreasing Costs, http://www.achi.net/Pages/News/Article.aspx?ID=35, accessed July 8, 2014.

20 Arkansas Department of Human Services, Arkansas Health System Transformation State Innovation Plan, 2012.

${ }^{21}$ Ibid.

22 Arkansas Insurance Department, Bulletin 3B-2013: Requirements for Qualified Health Plan Certification in the Arkansas Federally-Facilitated Partnership Exchange (Marketplace) (Little Rock, Ark.: Arkansas Insurance Department, June 2013), http://www.insurance.arkansas.gov/Legal/Bulletins/3B-2013.pdf, accessed June 27, 2014; Arkansas Insurance Department, Bulletin 9-2014: 2015 Plan Year Requirements for Qualified Health Plan Certification in the Arkansas Federally-Facilitated Partnership Marketplace (Little Rock, Ark.: Arkansas Insurance Department, April 2014), http://www.insurance.arkansas.gov/Legal/Bulletins/9-2014.pdf, accessed June 27, 2014.

23 D. Ramsey, "Nearly 200,000 Arkansans Have Gained Health Insurance Coverage via the Private Option for Medicaid Expansion,” Arkansas Times, Aug. 8, 2014, accessed Aug.10, 2014.

24 D. Ramsey, "Enrollment in Arkansas Health Insurance Marketplace at 44,665," April 22, 2014, accessed Aug. 10, 2014.

25 A. Allison, interview with Manatt, June 2014.

26 See, e.g., D. Bachrach, W. Bernstein, and A. Karl, High-Performance Health Care for Vulnerable Populations: A Policy Framework for Promoting Accountable Care in Medicaid (New York: The Commonwealth Fund, Nov. 2012).

27 In the first quarter of 2014, hospitals saw uncompensated care costs decrease by 30 percent with respect to hospital admissions and by 24 percent for emergency room use; M. Beebe, Governor Beebe's weekly column and radio address: Healthy Results, May 30, 2014, http://governor.arkansas.gov/newsroom/index.php?do:newsDetail=1\&news_id=4480, accessed June 27, 2014.

28 AHCPII was initially supported by a $\$ 1$ million grant from Arkansas Blue Cross Blue Shield that was matched with Medicaid funds. Thereafter, the state received a $\$ 42$ million grant from the Center for Medicare and Medicaid Innovation (CMMI) under the State Innovation Model (SIM) program. The state also benefited from its early participation in the CMMI's multipayer Comprehensive Primary Care initiative. 
29 Launched in July 2014, the IAP will develop strategies for advancing delivery system and associated payment reforms, aligned with transformation efforts under way in Medicare and the commercial market, Centers for Medicare and Medicaid Services, CMS Fact Sheets: Medicaid Innovation Accelerator Program, http://www.cms.gov/Newsroom/ MediaReleaseDatabase/Fact-sheets/2014-Fact-sheets-items/2014-07-14.html, accessed July 21, 2014.

30 Centers for Medicare and Medicaid Services, Comprehensive Primary Care Initiative: Arkansas: Statewide, http://innovation.cms.gov/initiatives/Comprehensive-Primary-Care-Initiative/Arkansas.html, accessed June 27, 2014.

31 Arkansas Insurance Department, Bulletin 3B-2013: Requirements for Qualified Health Plan Certification in the Arkansas Federally-Facilitated Partnership Exchange (Marketplace) (Little Rock, Ark.: Arkansas Insurance Department, June 2013), http://www.insurance.arkansas.gov/Legal/Bulletins/3B-2013.pdf, accessed June 27, 2014.

32 “Building a Healthier Future for All Arkansans: Arkansas SIM Site Visit,” June 12, 2013.

33 Golden, Thompson, Olson et al., "Patient-Centered Medical Homes in Arkansas," 2014.

34 Ibid.

35 Arkansas Department of Human Services, Arkansas Health System Transformation State Innovation Plan, 2012.

36 Golden, Thompson, Olson et al., “Patient-Centered Medical Homes in Arkansas,” 2014.

37 Ibid.

38 J. Selig, "Arkansas Health Care Payment Improvement Initiative," Presentation at the AcademyHealth National Health Policy Conference, Feb. 4, 2014, http://www.academyhealth.org/files/nhpc/2014/Pmt\%20Improv\%20for\%20 2-4-14\%20NHPC\%20conference.pdf, accessed June 27, 2014.

39 Arkansas Hospital Association Medicaid Subcommittee Meeting, June 5, 2014.

40 Arkansas Health Care Payment Improvement Initiative: Health Homes, http://www.paymentinitiative.org/healthHome/ Pages/Health-Homes.aspx, accessed July 21, 2014.

41 Arkansas Department of Human Services, Arkansas Health System Transformation State Innovation Plan, 2012.

42 C. Wilson and M. Motley, interview with Manatt, July 2014.

43 Arkansas Division of Medical Services, Arkansas Behavioral Health Home State Plan Amendment; Preliminary Working Draft, March 2014.

44 Arkansas Department of Human Services, Arkansas Health System Transformation State Innovation Plan, 2012.

45 J. Thompson, “The Nuts and Bolts of Arkansas Health Care: Crafting a New System,” Presentation at Children's Hospital Association Annual Leadership Conference, Oct. 14, 2013, http://www.childrenshospitals.net/Content/ ContentFolders34/EducationMeetings2/AnnualMeeting/2013/SessionsMonday/The_Nuts_and_Bolts_of_Arkansas_ Health_Care_Crafting_a_New_System_Presentation.pdf, accessed June 27, 2014.

46 The designated episodes currently paid under the new payment model include upper respiratory infection (three types), attention deficit hyperactivity disorder (ADHD), perinatal care, congestive heart failure, total joint replacement (hip and knee), colonoscopy, gall bladder removal, tonsillectomy, oppositional defiance disorder (ODD), coronary artery bypass grafting (CABG), and asthma. Others designated for future episode-based payments include percutaneous coronary intervention (PCI), chronic obstructive pulmonary disease (COPD), neonatal care, and ADHD/ODD comorbidity. State of Arkansas, Episode Spreadsheet with Notes: For Medicaid, Work Has Occurred on 24 Episodes, with 13 Having Gone Live, http://www.paymentinitiative.org/referenceMaterials/Documents/Episode\%20Spreadsheet\%20 -\%2024\%20with\%20notes.pdf, accessed July 8, 2014.

47 Thompson, Golden, Hill et al., "The Arkansas Payment Reform Laboratory," 2014. 
48 Arkansas Health Care Payment Improvement Initiative, Episode Summary: Total Hip and Knee Replacement (Little Rock, Ark.: AHCPII), http://www.paymentinitiative.org/referenceMaterials/Documents/hipKneeEpisode.pdf, accessed Aug. 11, 2014.

49 Arkansas Health Care Payment Improvement Initiative, Episodes of Care: Attention Deficit/Hyperactivity Disorder (ADHD): A Step by Step Guide (Little Rock, Ark.: AHCPII, 2014), accessed Aug. 11, 2014.

50 W. Golden, R. Griffin, J. Thompson et al., Arkansas Health Care Payment Improvement Initiative: Overview and the Role of Quality Measures (Little Rock, Ark.: Arkansas Foundation for Medical Care, July 2012), https://www.afmc.org/ LinkClick.aspx?fileticket=7R-jyQ-Vh0E\%3D\&tabid=683\&mid=1567, accessed June 27, 2014.

51 Thompson, Golden, Hill et al., “The Arkansas Payment Reform Laboratory,” 2014.

52 Ibid.

53 Arkansas Department of Human Services, Review Shows Payment Improvement Initiative Advancing Patient Care, Decreasing Costs, http://www.achi.net/Pages/News/Article.aspx?ID=35, accessed July 8, 2014.

54 Ibid. 


\section{ABOUT THE AUTHORS}

Deborah Bachrach, J.D., a partner with Manatt, Phelps \& Phillips, has more than 25 years of experience in health policy and financing in both the public and private sectors and an extensive background in Medicaid policy and health care reform. She works with states, providers, plans, and foundations in implementing federal health reform and Medicaid payment and delivery system reforms. Most recently, Ms. Bachrach was Medicaid director and deputy commissioner of health for the New York State Department of Health, Office of Health Insurance Programs. She has previously served as vice president for external affairs at St. Luke's-Roosevelt Hospital Center and as chief assistant attorney general and chief of the Civil Rights Bureau in the Office of the New York State Attorney General. Ms. Bachrach received her J.D. from New York University School of Law and a B.S. from the University of Pennsylvania, Wharton School.

Lammot du Pont is a senior advisor of Manatt Health Solutions (MHS), an interdisciplinary policy and business advisory practice of Manatt, Phelps \& Phillips, LLP. He provides business and technology strategy, planning and management services, and policy and communications advice to clients in the healthcare industry, with an emphasis on health information technology. Mr. du Pont has led the development of strategic and implementation plans for health information exchange for federal and state agencies, health information organizations, technology firms, and integrated delivery networks. Prior to joining Manatt Health Services, he served in the Office of the National Coordinator for Health Information Technology (ONC) at the U.S. Department of Health and Human Services.

Mindy Lipson, M.P.H., a senior analyst with Manatt Health Solutions, provides research, analysis, project support and strategic business services to health care providers and other health care organizations on a broad range of issues, including health care reform, public health insurance programs, health care delivery transformation, payment and reimbursement reform, and health information technology and exchange. Prior to joining Manatt Health Solutions, Ms. Lipson was a health research analyst at Mathematica Policy Research, where she was responsible for quantitative and qualitative data collection and analysis on a wide array of issues, including public health programs, state health policy, Medicare, and Medicaid. Ms. Lipson received an M.P.H. from the Mailman School of Public Health of Columbia University and a B.A. from Brandeis University.

Editorial support was provided by Hannah Fein. 
www.commonwealthfund.org 